Y.-S. CHENG, T. ZHANG, X. MA, S. PRATUANGTHAM, G. C. ZHANG, A. A. ONDRUS, A. MAFI, B. LOMENICK, J. J. JONES, A. E. ONDRUS* (CALIFORNIA INSTITUTE OF TECHNOLOGY, PASADENA, USA)

A Proteome-Wide Map of 20(S)-Hydroxycholesterol Interactors in Cell Membranes

Nat. Chem. Bio. 2021, 17, 1271-1280, DOI: 10.1038/s41589-021-00907-2.

\title{
Identifying the Long Sought-After Ligand of the Sigma-2 Receptor
}
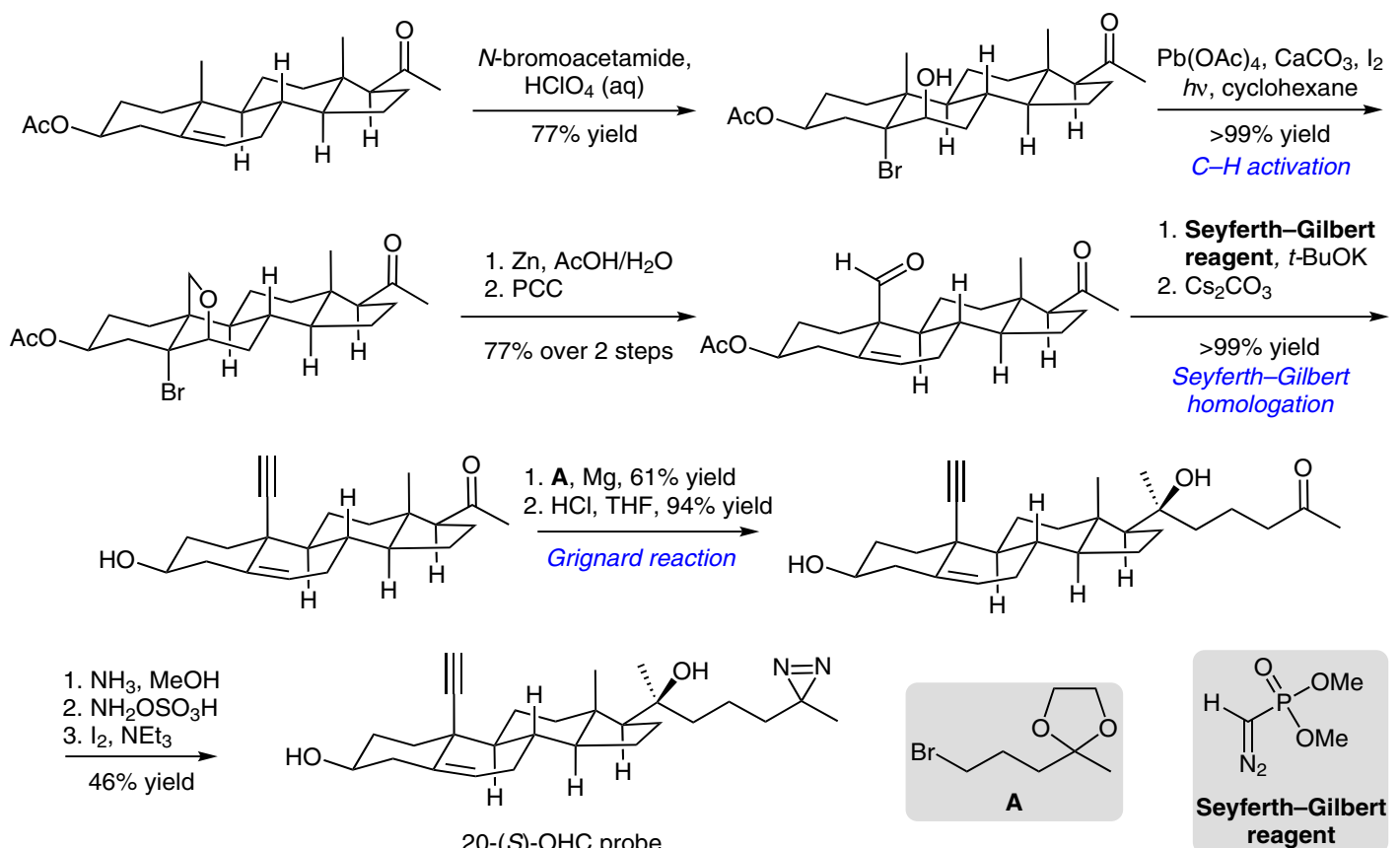

20-(S)-OHC probe

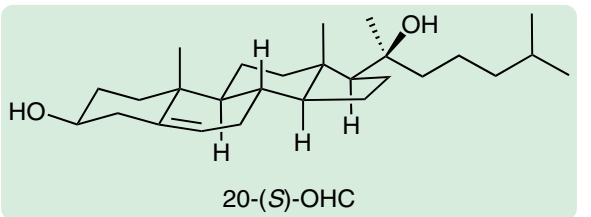

Significance: Oxysterols (OHCs) are short-lived metabolites of cholesterol that are present in low concentrations in the body. Evidence suggesting their roles as signaling molecules is growing. Identifying the targets of OHCs is synthetically challenging because it is difficult to make OHCs with selective oxidation patterns. Additionally, subtle changes to these molecules can drastically change the affinity to their targets and native membrane properties. Using a chemoproteomics probe of 20(S)-OHC that minimally perturbs its known function, the authors mapped the proteome-wide targets of 20(S)-OHC. Competition experiments showed that $20(S)-O H C$ is a chemo- and regioselective endogenous ligand of the sigma-2 receptor.
Comment: The 20-(S)-OHC probe was designed to contain a photoreactive diazirine to crosslink to proteins in live cells and a sterically minimal alkyne handle to attach affinity tags or fluorescent reporter molecules using click chemistry. The key steps in its synthesis included a photoinduced $\mathrm{C}-\mathrm{H}$ activation and Seyferth-Gilbert homologation to install the alkyne handle. Additionally, a selective Grignard reaction installs the side chain for the diazirine moiety, which was then formed in a one-pot procedure from the ketone.
Key words

chemoproteomics

$\mathrm{C}-\mathrm{H}$ activation

Seyferth-Gilbert homologation 